\title{
Research Paper: The Effect of Using Brace Combined With Low Level Laser Therapy on the Pain and Disability of People With Lateral Epicondylitis
}

Hedye Razi Kazemi ${ }^{1}$, Noureddin Karimi ${ }^{2}$, Fatemeh Honarmand ${ }^{1}$, Monireh Ahmadi Bani ${ }^{\text {* }}$ (iD)

1. Department of Orthosis and Prosthesis, University of Social Welfare and Rehabilitation Sciences, Tehran, Iran. 2. Department of Physiotherapy, University of Social Welfare and Rehabilitation Sciences, Tehran, Iran.

\begin{tabular}{|c|c|}
\hline $\begin{array}{l}\text { Use your device to scan } \\
\text { and read the article online }\end{array}$ & ditation Razi Kazemi H, Karimi N, Honarmand F, Ahmadi Bani M. The Effect of Using Brace Combined With Low Level \\
\hline 口ita & $\begin{array}{l}\text { Laser Therapy on the Pain and Disability of People With Lateral Epicondylitis. Physical Treatments. 2018; 8(3):153-160. http:// } \\
\text { dx.doi.org/10.32598/ptj.8.3.153 }\end{array}$ \\
\hline 0 & del : http://dx.doi.org/10.32598/ptj.8.3.153 \\
\hline
\end{tabular}

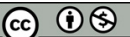

Article info

Received: 02 Jun 2018

Accepted: 29 Aug 2018

Available Online: 01 Oct 2018
Keywords:

Tennis elbow,

Lateral epicondylitis,

Counterforce brace, Low

level laser therapy, Grip

strength, Pain, Disability

\section{A B S T R A C T}

Purpose: Lateral Epicondylitis (LE) or tennis elbow is one of the most frequent complications in the general population. Moreover, it is one of the most common lesions in the work-related upper limb. This disease has a significant impact on the daily activities of individuals and their performance. The most frequent problem in patients with LE is pain in the proximal forearm. The current study evaluated and compared a simple proximal forearm strap and a counterforce brace combined with Low Level Laser Therapy (LLLT).

Methods: In this quasi-experimental study, 26 patients with LE were selected as samples using non-probability sampling technique (convenience method). They were randomly divided into the two groups of simple brace and brace+LLLT. Jamar Digital Hand Dynamometer, Visual Analog Scale, and the Disabilities of Arm, Shoulder and Hand (DASH) questionnaire were used to measure grip strength, pain and the disability of samples, respectively. The comparison of studied parameters was performed by repeated measures Analysis of Variance (ANOVA).

Results: The mean pain score significantly decreased in both groups; however, the difference between the two groups was not significant. The simple counterforce brace had no significant effect on grip strength, but in the group who used counterforce brace with LLLT, the grip strength significantly increased. The mean disability scores decreased significantly in both groups; however, the difference was not significant between the two groups. The counterforce brace with LLLT had more effect on the reduction of disability.

Conclusion: Both tested braces could affect grip strength, pain, and the disability of patients with LE. The counterforce brace with LLLT was superior to the simple counterforce brace only on grip strength.

\footnotetext{
* Corresponding Author:

Monireh Ahmadi Bani, PhD.

Address: Department of Orthosis and Prosthesis, University of Social Welfare and Rehabilitation Sciences, Tehran, Iran.

Phone: +98 (21) 22180010

E-mail:m.ahmadi002@gmail.com
} 


\section{Highlights}

- Lateral Epicondylitis (LE) or tennis elbow is caused by the excessive rotation of the forearm and or excessive use of extensor tendons.

- Using proximal forearm strap (circumferential forearm band, forearm strap, or forearm support band) is one of the most commonly used orthosis treatments.

- Among all different interventions, laser therapy, and proximal forearm strap have been reported as effective methods that reduce pain, increase grip strength, and improve performance and the quality of life in people with LE.

- The present study revealed a significant improvement in all three parameters of pain, grip strength, and disability in patients with LE after the treatment by both conventional and designed counter force braces.

\section{Plain Language Summary}

Laser therapy and proximal forearm strap have been reported as effective methods in reducing pain, increasing grip strength, and improving performance and the quality of life in people with lateral epicondylitis or tennis elbow. The present study revealed a significant improvement in all three parameters of pain, grip strength, and disability in patients with tennis elbow after the treatment by both conventional and designed counter force braces

\section{Introduction}

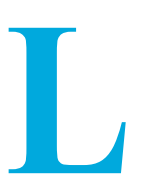

ateral Epicondylitis (LE) or tennis elbow is caused by the excessive rotation of forearm and excessive use of extensor tendons $[1,2]$. Its prevalence in the general population, in jobs requiring repetitive tasks, and in tennis players are $3-8 \%, 15 \%$ and $50 \%$, respectively. It is common in people aged $35-55$ years; it is almost twice as frequent in the dominant hand, compared to the non-dominant hand [3-5]. LE is one of the most common causes of lateral elbow pain. The amount of pain increases with active plantar extension, supination, grip strength, or resistance to wrist extension during exercise, daily activities and heavy work $[1,2]$.

Some common and effective treatments for LE include resting, non-steroidal anti-inflammatory medications, physiotherapy, exercise therapy, massage, corticosteroid injection (topical injection), ultrasound, laser therapy, braces, and surgery. Among these, laser therapy and proximal forearm strap have been reported as effective methods that reduce pain, increase grip strength, improve performance and the quality of life in people with LE [6].

Using proximal forearm strap (circumferential forearm band, forearm strap, or forearm support band) is one of the most commonly used orthosis treatments. It creates a secondary source and eliminates pressure on the muscle's primary source. Evaluating the combined effect of laser therapy and wearing braces has been neglected. Thus, this study examined the simultaneous effect of using Low Level Laser Therapy (LLLT) and proximal forearm strap on LE. Moreover, we compared its effect with a conventional counterforce brace that reduces the pressure and contraction on the muscle's primary source by creating a secondary source.

\section{Materials and Methods}

The study population consisted of patients with LE, who referred to clinics and private centers in Tehran City, Iran, in 2016. Of them, 26 were selected as study samples who aged 30-55 years [7] and reported pain in the lateral epicondyle of the humerus which aggravated by pressure on the epicondyle and was resistant to wrist extension. The exclusion criteria consisted of receiving any treatment for the condition in the past month; having a history of fracture, dislocation, half dislocation, osteoarthritis or elbow surgery [8]; limited elbow mobility, or suffering from arthritic diseases [5].

Of the 26 samples, one patient left the study. The remaining were divided into two groups randomly and using random number table. The remained 25 samples were randomly divided into two groups. By a random number table, the first group $(n=13$; Mean \pm SD age $=43.69 \pm 6.56$ y) used simple counterforce braces; they were all righthanded and $70 \%$ of them had involvement in the right 


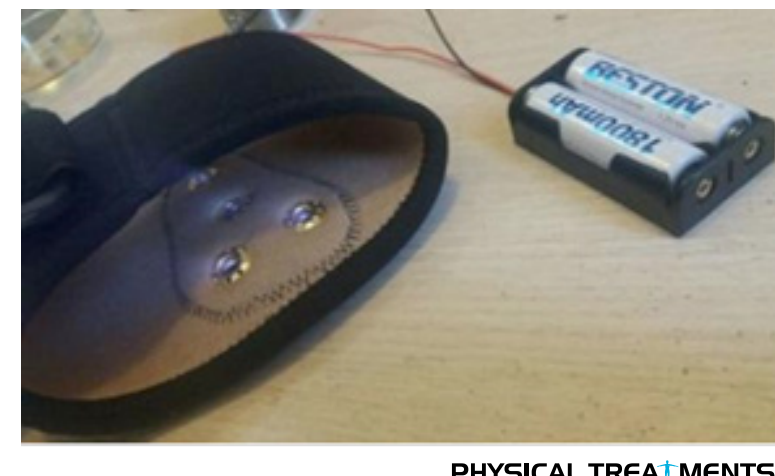

PHYSICAL TREA MENTS

Figure 1. Constructed counterforce brace with LLLT

hand. The second group participants ( $\mathrm{n}=12$; Mean $\pm \mathrm{SD}$ age $=45.25 \pm 7.30 \mathrm{y}$ ) used counterforce brace with LLLT; $83 \%$ of them were right-handed and $75 \%$ had involvement in the right hand. All of the study patients underwent clinical examinations for ensuring the correct diagnosis of disease $[9,10]$.

A duration of 4 weeks was considered to evaluate the effects of treatments on EL [11]. The study subjects were trained to use a simple counterforce brace for at least 6 hours per day and the designed brace for $30 \mathrm{~min}$ per day.

A tennis elbow brace with a low level laser (3 Jules and a 904-nm frequency) has been previously designed and constructed to simultaneously perform the orthotics and electrotherapy [12]. For this purpose, infrared LEDs have been used. For examining the simultaneous effect of laser therapy and brace, a new forearm strap was designed. The designed forearm strap consisted of a counterforce brace (available in different sizes) equipped with 4 LEDs, a socket and a rechargeable battery (Figure 1). Based on a predicted theory, infrared light which is currently used in physiotherapy can reduce inflammation and improve the recovery speed of damaged tissue. This process is the result of affecting the surface neuron terminals and increasing blood flow to tissues and the dispersion of accumulated materials causing pain in tissues. Moreover, orthotics decrease the forces in the epicondylar region by applying counterforce pressure on the muscular bulk at the bottom of lateral epicondyle; it can relieve pain and improve recovery speed.

To ensure the reliability of laser function, the patient was requested to look at the LEDs of brace in the day using a mobile camera (not iPhone) capable of recording infrared light. The laser therapy and its accuracy were followed-up by an experienced researcher during the treatment. No failure was reported. The researcher also checked the LEDs of all braces and observed that all were working correctly.
Clinical tests were performed and demographic characteristics were recorded. Moreover, to obtain clinical results on grip strength, pain and disability, Jamar Digital Hand Dynamometer, Visual Analog Scale (VAS), and the Disabilities of Arm, Shoulder, and Hand (DASH) questionnaire were used, respectively [13-16]. Clinical results were measured and compared once before the intervention and once after 4 weeks of use [11]. The digital dynamometer was first constructed by Bechtel Corporation in 1945 and is one of the most reliable tools to measure hand strength [14]. The patient holds the dynamometer in the hand and presses it three times for $5 \mathrm{~min}$ utes; eventually, the average score of three assessments is recorded. The VAS consists of a 10-cm line with labels at the end, as follows: "0" represents no pain, " $1-3$ ", mild pain; "4-6", moderate pain; and "7-10", severe pain [13]. The DASH questionnaire has 30 items with accep validity and reliability $[15,16]$.

Considering the normal data distribution (except for "grip strength" before using the conventional brace, and "disability" before using the designed brace), Paired Samples t-test and Independent Samples t-test were applied for comparing the obtained data. For the two variables $(\mathrm{P}<0.05)$, non-parametric tests were employed.

\section{Results}

Table 1 presents the descriptive statistics for age, height, weight, Body Mass Index (BMI), the involvement level of right and left hands, and the duration of brace use. No significant difference was observed between the two study groups in terms of age, weight, BMI, and the parameters of pain, disability and grip strength. This finding indicates the homogeneity and similarity of patients in the two groups.

The Mean \pm SD pretest grip strength score of those who used simple counterforce braces was $8.20 \pm 3.21$ which increased to $8.98 \pm 2.97$ after 4 weeks of use. In the study participants who used the counterforce braces with LLLT, the Mean \pm SD pretest grip strength score was $8.76 \pm 1.98$ and their Mean \pm SD posttest score was $12.48 \pm 1.98$. The improvement of grip strength was observed in both groups. Considering $\mathrm{P}=0.02$, there was a significant difference between the two groups $(\mathrm{P}<0.05)$.

The Mean \pm SD pain score in the group who used conventional braces reduced from $6.61 \pm 1.55$ before conducting the treatment to $3.76 \pm 1.87$ after the treatment. In the group who used braces with LLLT, the Mean \pm SD pain score reduced from $7.16 \pm 2.03$ to $2.58 \pm 0.99$ after the treatment. Both types of used braces could reduce pain in 
Table 1. The demographic characteristics of patients

\begin{tabular}{|c|c|c|c|}
\hline Underlying Factors & Group That Used a Simple Brace & Group That Used Brace With LLLT & $\mathbf{P}$ \\
\hline No. & 13 & 12 & - \\
\hline Age (yr) & $43.69 \pm 6.56$ & $45.25 \pm 7.30$ & 0.854 \\
\hline Weight (kg) & $69.00 \pm 8.08$ & $75.33 \pm 10.43$ & 0.103 \\
\hline Height $(\mathrm{cm})$ & $162.23 \pm 6.96$ & $167.83 \pm 10.55$ & 0.470 \\
\hline BMI $\left(\mathrm{Kg} / \mathrm{m}^{2}\right)$ & $26.27 \pm 3.47$ & $26.69 \pm 2.13$ & 0.334 \\
\hline Brace use duration (mon) & 9.76 & 9.41 & 0.628 \\
\hline Pain & $6.61 \pm 1.55$ & $7.16 \pm 2.03$ & 0.924 \\
\hline Disability & $48.27 \pm 11.18$ & $51.41 \pm 12.14$ & 0.438 \\
\hline Grip strength & $8.2 \pm 3.21$ & $8.76 \pm 1.98$ & 0.616 \\
\hline
\end{tabular}

Data are presented as Mean \pm SD.

PHYSICAL TREA $\ M E N T S$

the subjects; however, the difference between them was not statistically significant $(\mathrm{P}=0.66)$ (Table 2$)$.

Regarding the assessment of disability, the Mean \pm SD disability value significantly decreased in both groups $(\mathrm{P}<0.05)$. In the group who used simple braces, the pretest Mean \pm SD disability score was $48.27 \pm 11.18$; after 4 weeks of use, it was reported equal to $34.92 \pm 0.19$. In the group who used designed braces, the Mean \pm SD disability scores reduced from $51.41 \pm 14.51$ to $33.58 \pm 10.84$ after conducting the treatment. However, the difference between the two groups was not statistically significant $(\mathrm{P}=0.75)$ (Table 2).

\section{Discussion}

The present study revealed a significant improvement in all three parameters of pain, grip strength and disability in patients with LE after the treatment by both conventional and designed counterforce braces (no sig- nificant improvement was found in grip strength variable before and after using conventional braces). Both braces could significantly improve pain and performance in the study participants; however, no significant difference was reported between the two tested braces. Only in terms of grip strength, the designed forearm strap with LLLT had significant effects, compared to its conventional type $(\mathrm{P}=0.02)$. Although it also improved pain and reduced disability in the patients with $L E$, its effect was not statistically significant. Due to the small sample size and short project duration, only the short-term effects of treatments were evaluated. By increasing the sample size and study duration, and considering the closeness of the results in examining the two parameters of pain and disability, more reliable data can be obtained.

The obtained result regarding the effectiveness of simple counterforce braces is consistent with the results of Bisset et al., Garg et al., Sadeghi-Demneh and Jafarian and Altan and Kanat [4, 17-19]. They all indicated the

Table 2. Comparing the effects of conventional and designed counterforce braces on pain, disability, and grip strength

\begin{tabular}{cccc}
\hline Underlying Factors & Brace & Pretest & Posttest \\
\hline Grip strength $(\mathrm{kg})$ & Simple counterforce brace & $8.20 \pm 3.21$ & $8.98 \pm 2.97$ \\
& Counterforce brace with LLLT & $8.76 \pm 1.98$ & $12.48 \pm 1.98$ \\
\cline { 2 - 2 } & Simple counterforce brace & $6.61 \pm 1.55$ & $3.76 \pm 1.87$ \\
Pain & Counterforce brace with LLLT & $7.16 \pm 2.53$ & $2.58 \pm 0.99$ \\
Disability & Simple counterforce brace & $48.27 \pm 11.18$ & $34.92 \pm 5.19$ \\
& Counterforce brace with LLLT & $51.41 \pm 14.51$ & $33.58 \pm 10.84$
\end{tabular}

Data are presented as Mean \pm SD.

PHYSICAL TREA $\ M E N T S$ 
effect of a forearm strap on the reduction of pain. Applying a conventional tennis elbow brace is helpful in reducing pain due to changing the original source of the extensor compartment muscles of the forearm. By this change, the inflamed part of the muscle relaxes and pain is reduced, consequently.

Results of Chang et al., Lam and Cheing, and Bjordal et al. who investigated the effect of LLLT are in line with our findings regarding pain assessment [20-22]. Histological studies suggested that after laser radiation, the amount of prostaglandin E2 decreases dramatically; thus, it prevents vessel dilation and inflammation [3]. According to Lam and Cheing, and Bjordal et al. LLLT is a safe and effective method [21, 22]. By increasing blood flow and improving tissue oxygenation, it prevents hypoxia and tissue fatigue and reduces pain in the trigger points $[3,21]$. Our obtained results were inconsistent with the results of Basford et al. (2000). This is because after using LLLT, they found no difference in pain score between the treated and untreated subjects. In the study of Dundar et al., a significant reduction in pain has been reported after using brace and laser therapy [6].

Two meta-analysis studies reported positive effects of treatment with counterforce brace on the improvement of pain and grip strength [23]. Our obtained results regarding grip strength are consistent with the findings of Lam [24], but inconsistent with those of Dundar and colleagues [6]. They reported no significant difference between the group using lateral counterforce brace and those receiving high-intensity laser therapy, in terms of grip strength. Bisset et al. compared two types of brace (simple proximal forearm brace vs. elbow brace). In line with our obtained data, they reported the conventional brace immediately increases the grip strength. However, there was no significant difference between the brace users and controls [4]. Relieved pain and reduced inflammation can be possible reasons for improved grip strength. Muscles involved in gripping strength were improved using braces and showed increased strength. Therefore, the use of both brace and laser therapy can be considered as non-invasive, painless, affordable, accessible, and accepted interventions.

In respect of disability evaluation, our results are consistent with the findings of Struijs et al. [25]. They argued that the combination of brace treatment and physical therapy was superior to brace-only treatment on disability. The results of Bjordal et al. are also in agreement with this investigation [22]. They also reported less disability in groups using LLLT and braces. Reduced pain and increased strength in patients using braces are reasons for increased performance. Therefore, disability is likely to be reduced after pain relief. Individuals using braces, with less pain, are more capable of performing daily living activities and can perform their duties with more strength and less pain. In the study of Basford et al. (2000), no significant difference was reported between LLLT and placebo groups in terms of performance; this can be due to their small sample size and short follow-up period.

There were several limitations to this study. Data on the simultaneous effect of brace and LLLT and their combined effect on people with LE are scarce. Moreover, there are contradictory results about the impact of LLLT on LE regarding dose, the duration of use and the frequency of laser $[21,26]$. Some studies have also indicated the ineffectiveness of LLLT on LE [27, 28]. Not evaluating the long-term effects of using braces due to the time constraints, and having difficulty with preparing LEDs were other limitations of this study.

Future investigations are recommended to explore the long-term effects of braces on the studied variables. To determine which brace had a longer-lasting effect, designing a new brace combined with counterforce brace and wrist splint, as well as using both simultaneously, are suggested. Considering a larger sample size is also recommended.

Both studied braces could affect the three parameters of pain, disability and grip strength after 4 weeks of use. Their comparison suggested that counterforce brace with LLLT was superior to a simple counterforce brace only on grip strength.

\section{Ethical Considerations}

\section{Compliance with ethical guidelines}

All ethical principles were considered in this article. The participants were informed about the purpose of the research and its implementation stages; They were also assured about the confidentiality of their information; Moreover, They were allowed to leave the study whenever they wish, and if desired, the results of the research would be available to them.

\section{Funding}

This project was funded by University of Social Welfare and Rehabilitation Sciences. 


\section{Authors' contributions}

All authors contributed in designing, running, and writing all parts of the research.

\section{Conflict of interest}

The authors declared no conflict of interest.

\section{References}

[1] Najafi M, Arazpour M, Aminian G, Curran S, Madani SP, Hutchins SW. Effect of a new hand-forearm splint on grip strength, pain, and function in patients with tennis elbow. Prosthetics and Orthotics International. 2016; 40(3):363-8. [DOI:10.1177/0309364615592694] [PMID]

[2] Nimura A, Fujishiro H, Wakabayashi Y, Imatani J, Sugaya $\mathrm{H}$, Akita K. Joint capsule attachment to the extensor carp radialis brevis origin: An anatomical study with possible implications regarding the etiology of lateral epicondylitis. The Journal of Hand Surgery. 2014; 39(2):219-25. [DOI:10.1016/j. jhsa.2013.11.036] [PMID]

[3] Radpasand M. Combination of manipulation, exercise, and physical therapy for the treatment of a 57-year-old woman with lateral epicondylitis. Journal of Manipulative and Physiological Therapeutics. 2009; 32(2):166-72. [DOI:10.1016/j. jmpt.2008.12.007] [PMID]

[4] Bisset LM, Collins NJ, Offord SS. Immediate effects of 2 types of braces on pain and grip strength in people with latera epicondylalgia: A randomized controlled trial. Journal of Orthopaedic \& Sports Physical Therapy. 2014; 44(2):120-8 [DOI:10.2519/jospt.2014.4744] [PMID]

[5] Forogh B, Khalighi M, Javanshir MA, Ghoseiri K, Kamali M, Raissi G. The effects of a new designed forearm orthosis in treatment of lateral epicondylitis. Disability and Rehabilitation: Assistive Technology. 2012; 7(4):336-9. [DOI:10.3109/1 7483107.2011.635330] [PMID]

[6] Dundar U, Turkmen U, Toktas H, Ulasli AM, Solak O. Effectiveness of high-intensity laser therapy and splinting in lateral epicondylitis; A prospective, randomized, controlled study. Lasers in Medical Science. 2015; 30(3):1097-107. [DOI:10.1007/s10103-015-1716-7] [PMID]

[7] Van De Streek M, Van Der Schans C, De Greef M, Postema $K$. The effect of a forearm/hand splint compared with an elbow band as a treatment for lateral epicondylitis. Prosthetics and Orthotics International. 2004; 28(2):183-9. [DOI:10.1080/03093640408726703] [PMID]

[8] Jafarian FS, Demneh ES, Tyson SF. The immediate effect of orthotic management on grip strength of patients with lateral epicondylosis. Journal of Orthopaedic \& Sports Physical Therapy. 2009; 39(6):484-9. [DOI:10.2519/jospt.2009.2988] [PMID]

[9] Ahmad Z, Siddiqui N, Malik S, Abdus-Samee M, Tytherleigh-Strong G, Rushton N. Lateral epicondylitis: A review of pathology and management. The Bone \& Joint Journal.
2013; 95(9):1158-64. [DOI:10.1302/0301-620X.95B9.29285] [PMID]

[10] Walz DM, Newman JS, Konin GP, Ross G. Epicondylitis: Pathogenesis, imaging, and treatment. Radiographics. 2010; 30(1):167-84. [DOI:10.1148/rg.301095078] [PMID]

[11] Bjordal JM, Couppe C, Ljunggren AE. Low level laser therapy for tendinopathy. Evidence of a dose- response pattern. Physical Therapy Reviews. 2001; 6(2):91-9. [DOI:10.1179/ ptr.2001.6.2.91]

[12] Bani M, Arazpour M, Tomaj Y. Design and construction of a tennis elbow brace with light-emitting diode in subjects with lateral epicondylitis. Journal of Hand Therapy. 2019; 32(1):124-7

[13] Schofield P. The management of pain in older people. Hoboken: John Wiley \& Sons; 2007.

[14] Watts A, Greenstock M, Cole R. Outcome following the rehabilitation of hand trauma patients: The importance of a subjective functional assessment. Journal of Hand Surgery. 1998; 23(4):485-9. [DOI:10.1016/S0266-7681(98)80128-9]

[15] Rompe JD, Overend TJ, MacDermid JC. Validation of the patient-rated tennis elbow evaluation questionnaire Journal of Hand Therapy. 2007; 20(1):3-11. [DOI:10.1197/j. jht.2006.10.003] [PMID]

[16] Nilsson P, Baigi A, Marklund B, Månsson J. Cross-cultura adaptation and determination of the reliability and validity of PRTEE-S (Patientskattad Utvärdering av Tennisarmbåge), a questionnaire for patients with lateral epicondylalgia, in a Swedish population. BMC Musculoskeletal Disorders. 2008, 9(1):79. [DOI:10.1186/1471-2474-9-79] [PMID] [PMCID]

[17] Garg R, Adamson GJ, Dawson PA, Shankwiler JA, Pink MM. A prospective randomized study comparing a forearm strap brace versus a wrist splint for the treatment of lateral epicondylitis. Journal of Shoulder and Elbow Surgery. 2010; 19(4):508-12. [DOI:10.1016/j.jse.2009.12.015] [PMID]

[18] Sadeghi-Demneh E, Jafarian F. The immediate effects of orthoses on pain in people with lateral epicondylalgia. Pain Research and Treatment. 2013; 2013(353597):1-6. [DOI:10.1155/2013/353597]

[19] Altan L, Kanat E. Conservative treatment of lateral epicondylitis: Comparison of two different orthotic devices. Clinical Rheumatology. 2008; 27(8):1015-9. [DOI:10.1007/s10067008-0862-8] [PMID]

[20] Chang WD, Wu JH, Yang WJ, Jiang JA. Therapeutic effects of low-level laser on lateral epicondylitis from differential interventions of Chinese-Western medicine: Systematic review. Photomedicine and Laser Surgery. 2010; 28(3):327-36 [DOI:10.1089/pho.2009.2558] [PMID]

[21] Lam LKY, Cheing GLY. Effects of 904-nm low-level laser therapy in the management of lateral epicondylitis: A randomized controlled trial. Photomedicine and Laser Surgery. 2007; 25(2):65-71. [DOI:10.1089/pho.2006.2047] [PMID]

[22] Bjordal JM, Lopes-Martins RA, Joensen J, Couppe C, Ljunggren AE, Stergioulas A, et al. A systematic review with procedural assessments and meta-analysis of low level laser therapy in lateral elbow tendinopathy (tennis elbow). BMC Musculoskeletal Disorders. 2008;9(1):75. [DOI:10.1186/14712474-9-75] [PMID] [PMCID] 
[23] Cameron MH. Physical agents in rehabilitation: From research to practice. Amsterdam: Elsevier Health Sciences; 2012.

[24] Öken Ö, Kahraman Y, Ayhan F, Canpolat S, Yorgancioglu ZR, Öken ÖF. The short-term efficacy of laser, brace, and ultrasound treatment in lateral epicondylitis: A prospective, randomized, controlled trial. Journal of Hand Therapy. 2008; 21(1):63-8. [DOI:10.1197/j.jht.2007.09.003] [PMID]

[25] Struijs P, Kerkhoffs G, Assendelft W, van Dijk CN. Conservative treatment of lateral epicondylitis: Brace versus physical therapy or a combination of both- A randomized clinical trial. The American Journal of Sports Medicine. 2004; 32(2):462-9. [DOI:10.1177/0095399703258714] [PMID]

[26] Saptarshi Basu M, Hassenplug JC. Archive for the 'valves \& tools' category. The New England Journal of Medicine. 2012; 367(6):485-8. [PMID]

[27] Stasinopoulos DI, Johnson MI. Effectiveness of low-level laser therapy for lateral elbow tendinopathy. Photomedicine and Laser Therapy. 2005; 23(4):425-30. [DOI:10.1089/ pho.2005.23.425] [PMID]

[28] Basford JR, Sheffield CG, Cieslak KR. Laser therapy: A randomized, controlled trial of the effects of low intensity $\mathrm{Nd}$ : YAG laser irradiation on lateral epicondylitis. Archives of Physical Medicine and Rehabilitation. 2000; 81(11):1504-10. [DOI:10.1053/apmr.2000.17812] [PMID] 
This Page Intentionally Left Blank 